\title{
COVID-19 PANDEMIC AND DIGITALIZATION OF HEALTHCARE AMONG YOUTH: A MARKETING PERSPECTIVE
}

\author{
Ankita Gaur ${ }^{1}$, Rajiv Tonk ${ }^{2}$ \\ ${ }^{1,2}$ School of Pharmaceutical Sciences, Delhi Pharmaceutical Sciences and Research University, \\ Delhi-110 017, India
}

Corresponding Author: Rajiv Tonk

Article DOI: https://doi.org/10.36713/epra8267

DOI No: 10.36713/epra8267

\begin{abstract}
The term "digital" has been ingrained in our culture. At a quicker rate than the rest of the world, every industry has adapted to the digital era. Apart from the website, the pharmaceutical sector has yet to fully embrace digital marketing. More pharmaceutical and healthcare firms are using social media sites or eCommerce sites as digital marketing platforms in the wake of the Corona Virus pandemic. Some businesses are attempting to comprehend the actual worth of digital, while others are incorporating it into their whole marketing plan. In the pharmaceutical and healthcare industries, digital marketing is displacing traditional marketing techniques. This research looked at a variety of topics, including marketing among youth, the present role of digital marketing in the pharmaceutical business, the influence of COVID-19, and current consumer buying behavior. The main goal is to learn about the past, comprehend the current shift, and forecast the consequences of pharmaceutical marketing in the future. This is accomplished by doing a thorough literature review and then presenting a questionnaire based on the findings for validation among the general public.

KEY WORDS: Marketing, Health Services, Pharmaceuticals, COVID-19, Pandemic, Youth
\end{abstract}

\section{INTRODUCTION}

Healthcare or pharmaceutical marketing is a broad discipline that includes both general and specific knowledge of marketing and business activities related to products/services in the fields of medicine, therapy, and patient/citizen/buyer health improvement, with profits going to the society and organisations that provide the product/service. These products are responsible for people's health. They are subject to stringent and unique regulations on their way to market, beginning with manufacturing regulations, quality control, distribution, a premarketing phase, registration procedure, marketing licence, and tracking the medicine after it has been released.

We live in a digital world, which has become even more so during the COVID-19 pandemic, in which people rely more on smart gadgets and spend more time online seeking information. According to some studies, 95 per cent of consumers now compare and check product or service reviews before making a purchase (McCabe Kristen, 2020), while Google claims that up to 77 per cent of patients consult the Internet before making a decision (Yasgur Batya Swift, 2019). As a result, an increasing number of health organisations realise the need to have an online presence and use digital platforms to attract new consumers. When it comes to making critical decisions, the 18-25 age group, known as the youth, trusts social media. Benefits include the ability for health organisations to quickly market a product or service to a particular demographic, as well as the ability to choose who to target for preventative programmes and services. One can quickly measure and optimise outcomes in the digital world, as well as obtain reliable statistics on a wide range of activities.

The current study aims to identify the effect of COVID-19 on the Digitalization of Healthcare, thereby Pharmaceutical Marketing, and cater to understand the 
emerging markets in this sector. The variation in marketing campaigns and consumer perspectives for consumer products and healthcare products/services, including pharmaceutical products, devices, and other services shall also be studied. The survey under the study is designed for a comparative analysis of youth's perspectives on pre-and post-COVID-19 buying behaviour focusing on healthcare products and services. It is expected that this study will confirm how COVID-19 has transformed pharmaceutical marketing among the youth strata of the population.

\section{COVID-19 IMPACT ON THE PHARMACEUTICAL AND HEALTHCARE INDUSTRY}

Currently, the COVID-19 pandemic is a worldwide economic catastrophe impacting virtually everyone, including healthcare. There are significant challenges to physical and mental breakdowns among health care professionals and insufficient healthcare infrastructure and services. The most common chances of being infected with the virus are healthcare personnel, notably dentists, gastroenterologists, pulmonologists, respiratory therapists, speech therapists, infectious medicine and ophthalmologists. (Meng, L et. al, 2020, Ran, L et al, 2020, and Lai, T.H.T. et al, 2020) Furthermore, doctors and other healthcare workers are always concerned that infection may occur and the death of infected patients alone has helped to exacerbate their depressive and anxious feelings (Chen. F., 2020). Health services are interfered with internationally in many areas; it has been customary to communicate with patients outside of clinics to ensure safety measures. In addition, it was also seen to pose an additional problem in the scenario that medication producers were unable to acquire active pharmaceutical products from Chinese companies. The catastrophic breakdown of trade and travel throughout the world has harmed the current economy.

This pandemic affected considerably the delivery of outpatient treatment; the visits of patients were postponed to reduce the danger that patients and healthcare professionals would have received. Whenever feasible, doctors have shifted away from distant visits to personal visits. This is a huge problem for individuals with a chronic disease that requires regular visits, control and monitoring. Healthcare staff and facilities are unable to get treatment. Many patients are urged to stay home, avoiding exposure to clinics and hospitals. Due to these circumstances, it was time and trend which became obvious by the number of medical companies and pharmaceutical companies entering the digital area that became necessary for the online alternatives. These firms are striving to achieve the digital marketing technique to gain this place in the market.

\section{MARKETING CONCEPTUALIZATION}

A market may be defined in a variety of ways, which is why there are so many different definitions of what a market looks like. While some academics claim that a market is essentially homogenous, as in a supply-demand equilibrium, others argue that it is more heterogeneous, as in a more complex network with more players who are somehow connected. Manufacturers, suppliers, merchants, and customers are just a few examples (Wagrell, 2018). Furthermore, there are two perspectives when it comes to viewpoints: the conventional view and the network view. Kotler, a well-known marketing guru, produced the original. The conventional concept of a market is that it is impersonal and has defined borders; it is also described as a space where two independent individuals trade a commodity (Wagrell, 2018). From the perspective of a network, the players are interconnected and part of a greater whole (Håkansson and Shenota, 1995).

\section{THE "MARKETING MIX" AND ITS TRANSFORMATION OVER THE YEARS}

In the 1960s, the phrase "marketing mix" was used to characterise the traditional marketing strategy. The marketing mix is made up of four elements: product, price, place, and promotion. The 4Ps of marketing refers to these four components. The product is the actual thing that the business wants to sell to the customer, or, to put it another way, what the customer wants from the business. A client's willingness to spend a certain amount of money on a product is referred to as pricing. Product marketing and displays that a company may provide to its customers are examples of promotion (Philip Kotler, Hermawan Kartajaya, 2017; Yi, 2018). The 7Ps are a more thorough version of the 4Ps. The four Ps (product, price, place, and promotion) are the same as the previously stated four Ps. However, the additional three Ps are People, Process, and Physical Evidence. People are integrally engaged in how the product will delight the customer, whether they represent the person who gives the product or the person who gets it. The process refers to how the product is supplied to the customer. Finally, the location where the things are handed over is regarded as tangible proof or physical evidence (Yi, 2018). The $7 \mathrm{Ps}+1 \mathrm{G}$ is a newer version, with the $1 \mathrm{G}$ standing for Green Marketing. This latest version, 7Ps and $1 \mathrm{G}$ is all new and targeted at internet marketing (Pistol and Ţoniş Bucea-Manea, 2017).

\section{THE MAJOR DIVISION OF MARKETING STRATEGIES}

Business to consumer or business to business marketing are two terms used to describe marketing. Business to consumer marketing is when a corporation or organisation markets directly to a product or service's enduser. When commerce is done between organisations or corporations, it is referred to as business to business. When comparing $\mathrm{B} 2 \mathrm{~B}$ with $\mathrm{B} 2 \mathrm{C}$ marketing, it is clear that $\mathrm{B} 2 \mathrm{C}$ frequently conducts transactions while the client is on the
(C) 2021 EPRA EBMS | www.eprajournals.com 
website, but B2B seldom conducts transactions through the website and instead conducts transactions between people (Chaffey and Ellis-Chadwick, 2016, p. 21). According to Chaffey and Ellis-Chadwick (2016, p. 629), there are four distinct customer-generation ideas in B2B marketing. "Stage 1: Search marketing, online PR, and display advertising are utilised to drive traffic to a website. Stage 2: Visitors are encouraged to connect with the site and share knowledge via social media using engagement devices such as videos, white papers, or other kinds of market education content. Stage 3: Providing visitors with access to important permission-based material is utilised to create leads by persuading them to register on the site, provide an e-mail address and profile information, or share the content via social media. Stage 4: Leads are followed up on using tailored e-mail sequences or, if applicable, outbound phone calls to qualify them as valuable leads". The four steps represent a "permission-based" marketing strategy, often known as content marketing or inbound marketing in B2B marketing.

\section{DIGITALIZATION OF MARKETING STRATEGIES OVER LAST DECADE}

Internet marketing, E-marketing, and online marketing are all terms used to describe digital marketing. However, most papers refer to it as digital marketing, which we shall utilise in this study as well. The marketing approach is based on the rise of digital media, which encompasses a variety of digital platforms such as interactive television, the Web, mobile phones, and the Internet (Chaffey and Ellis-Chadwick, 2016). When the World Wide Web (WWW) and the following websites became publicly available in 1991, it marked the beginning of a field that would eventually disrupt traditional marketing. With over 3 billion people utilising the internet today, digital marketing has become a must-have for any business. Since online and offline operations can go hand in hand, B2B marketing might have an opposing viewpoint on digital marketing. Furthermore, because B2B digital marketing research is scarce, it may be argued that B2C marketing benefits far more from the existing data than B2B marketing. According to the findings, some practitioners profit entirely from digital marketing, while others engage in both traditional and digital marketing (Popovici et al., 2018). Today, the rise of digital marketing is rising year after year. As a result, digital marketing is becoming increasingly important for businesses (Silverman, 2019). When comparing the advantages of digital marketing to conventional marketing, consider the ability of digital marketing to target individuals or organisations that are most likely to become consumers. If a firm focuses its marketing resources on individuals who become customers, it demonstrates that it has a successful marketing strategy and makes efficient use of its marketing resources, allowing the intended people to find the webpage using a search engine. As keywords are important, it's important to use them correctly (Anderson et al., 2019; Chaffey and Ellis-Chadwick, 2016). However, not all businesses are succeeding in this area, and data reveals that one industry, in particular, the healthcare industry, is falling behind in terms of digital marketing (Grbic et al., 2019). There is a need to look into why this industry's firms are underperforming. Without a doubt, the present pandemic scenario has provided an opportunity to develop and catch up with other businesses, but there is still a gap to fill.

\section{DIGITALIZATION OF HEALTHCARE MARKETING AMID COVID-19}

In India, medical firms must work diligently on their marketing tactics to establish and retain consumer interaction. As discussed, traditional marketing can not be implemented due to a nationwide lockdown and, therefore, digital marketing is given greater importance. The current study focuses on all the important dimensions of digital marketing in the pharmaceutical and healthcare sectors that have been implemented or can be implemented to improve the effectiveness of marketing in today's times. As a result of the understanding of currently available literature, a few major strategic viewpoints have come to light that can potentially help brands bloom over the internet during this time. The goal of this research is to link the following theoretical consequences to real customer behaviour through primary research.

1. Service Positioning: Adding a social message and relating the image of the product/service to overall wellness is deemed vital during the Pandemic. To have a better understanding of the product and its competitive marketplace, it is necessary to perform online marketing research and competitor research. Following this procedure, the firm will create a brand/product picture that will reflect the company's core message, in which it will use a certain style of writing persuasive messages to attract their target audience by using key phrases and posting them on relevant sites and online properties. Several epharmacies have embraced this technique by altering their logos to conform to COVID-19 safety requirements, and others have included wellness messaging to urge people to follow the procedures while keeping an eye on their health.

2. Digital Marketing Tools: Platforms such as Google Analytics, Sponsored Searches, Ad Groups, and others aid in the evaluation and invitation of a client base. It is undeniably a talent for creating a demand for information that has to be released. There are numerous e-commerce web design solutions available to boost a brand's potential web traffic. Keyword research is critical for increasing online traffic to a certain website. Striving to provide highquality material to the public would increase the site's mind share and help the audience expand as a result of the company's new concept.

(C) 2021 EPRA EBMS | www.eprajournals.com 
3. Relevant Content: The expansion of the audience is aided by the constant use of relevant photos and original material. Professional content writers and digital marketing companies play an important part in shaping the product's image. The content presented should encourage the audience to share and spread the message to the rest of the world. Various firms have worked diligently in this area of marketing over the past two years to build a favourable brand image in the minds of potential customers. This might include everything from basic well-being messaging to innovative ways of communicating information, myth busters, and service-specific elements like data on the number of individuals who have booked or utilised various services such as lab tests, immunity boosters, and preventive medications.

4. Keeping touch with the audiences: To attract and maintain new and existing customers, a deliberate effort must be made to generate fresh material regularly, such as blogs, newsletters, videos, articles, and press releases, to keep the audience up to date on the latest product advancements.

5. Celebrity Involvement: It is critical to forming alliances with corporations and other influencers who contribute to the growth or visibility of digital media to expand digital media. Brand ambassadors and social media networks put in a lot of effort to find the finest partnerships to promote the product.

\section{OBJECTIVE}

The impact on marketing has been substantial as a result of the current global scenario. To adapt to the circumstances, healthcare brands have to change their business strategies. Marketing, being one of the most essential parts of a company's growth, must be thoroughly examined to properly place the product/service in the market.

The ultimate aim is to assess the influence of COVID-19 on healthcare digitalization and marketing, as well as to understand how marketing strategies have evolved as a consequence. The study also aims to clarify the differences and issues that exist in consumer and healthcare/pharmaceutical product marketing. The study's main focus is on young people aged 18 to 25 , who are one of the most important contributors to the growth of digital marketing. The survey questionnaire will allow a comparison of adolescent buying behaviour before and after COVID-19, which will aid in accessing new emerging markets in healthcare and explain the potential buyer's perspective.

The following are the research topics that will be examined and addressed through this study: How will COVID-19 alter youth-targeted pharmaceutical marketing?

- What percentage of this group accepts the shift from offline to online mode?
- Where does the bulk of the populace stand in this change right now?

- What elements of their everyday lives do they accept moving online?

- What marketing tactics are most likely to make a change in the way people buy healthcare products and services?

- How probable is it that the marketing techniques will influence the sale of the product in question?

- What is the most commonly recognised method for retrieving and updating information?

\section{METHODOLOGY}

The research alternates between theory and actual data. Therefore, a combination of deductive and inductive techniques will be the most effective. The general technique in this study is abductive, which is frequent, especially in qualitative research, and is a way theory and data interact back and forth (Brantnell, 2019). The socalled deductive method, which is a connection between theory and research, formed the basis for the applied research approach at first. Whereas theory is concerned with the development of hypotheses that are experimentally tested (Bryman and Bell, 2011). One of the most frequent techniques in quantitative research is the deductive approach. Furthermore, because the subject of digital marketing is still relatively young and evolving, the deductive method was followed by an inductive approach. The empirical data in this example, both qualitative and quantitative, contributed to the relatively unknown sector of digital marketing in the healthcare business. This might include parts of the study that were not covered in the theory or literature; hence, the inductive technique is frequently utilised in qualitative investigations. The abductive approach is the most appropriate choice since the study is based on a theoretical framework but confirmed via actual evidence.

The research was carried out in stages during its completion. The research was split into two sections: a literature review and a targeted survey. The author hoped that by presenting a complete image of the situation to the reader, they would be able to contribute value to the study they were conducting.

The review was conducted by employing keywords COVID-19, Marketing, Pharmaceuticals, Youth, Digitalization, and Digital Marketing to restrict the search results in Google Scholar and PubMed. The timeframe was not set in stone so that, a comparison of old and current pharmaceutical marketing strategies could be made. With a 95\% confidence interval and a $7.5 \%$ margin of error, the youth survey can represent the $35,00,000$ population of persons aged 15-25 in Delhi NCR. It was intended to get equal representation from both genders so that it would not be perceived as a barrier. Responses to the survey other than the stipulated age group (15-25 years) were not 
included in the analysis.

\section{RESULTS}

The survey has ten questions in all, three of which were designed to limit participants' demographics to collect data from the target group, which is the youth of the Delhi NCR region. The demographic picture of the responses is fairly acceptable, and it seems unlikely that this is a research constraint. In all, 210 individuals (112 females = $53 \%$; 98 males $=47 \%$ ) answered the survey, with the bulk of them being students (89\%), followed by full-time employees $(6 \%)$, unemployed $(3 \%)$, self-employed $(2 \%)$, and part-time employees $(1 \%)$. This offers the researcher an indication of the differences in answers based on gender and current status classification. These particulars, however, were omitted during the general data analysis since the study was focused on the marketing perspective.

The respondents were asked which method of choice they preferred for daily activities, online or offline, to see if they completely accepted the online or digital manner. Several non-healthcare variables were also added to prevent bias and to better evaluate acceptability. According to the data, they feel comfortable transitioning from offline to online mode for laboratory testing, doctor consultations, and prescription purchasing, as well as other products, shopping, banking, and money transactions, which supports the fact that there is a favourable change. The only thing that did not follow this shift was studying and reading. Money transactions were rated highest and medical consultations ranked lowest in terms of acceptance per cent, while pharmaceutical shopping and lab testing were placed in the middle. Based on the statistics, we may deduce that this population's general acceptability of our area of concern lies mid-way. The next question asked the responders to rate themselves on a five-point scale. Where 1 and 5stand for "I prefer offline" and "I prefer online mode", respectively.

Figure 1 plainly shows that the bulk of the population is in the centre, and the trendline shows that there is a good chance that people will move forward and adopt contemporary techniques.

According to the literature, various elements influence a consumer's decision to buy on a certain platform. The respondents were asked to assess the frequency with which the given variables influenced their decisions.

According to the facts provided in Table 1, the most significant elements that always and mostly influence the target demographic are product quality and variety, respectively, whereas TV advertisements have the least impact. This is a good result, indicating that traditional marketing methods are not assisting companies in making an impression, particularly among this group. Furthermore, it is to be noted that social media is not in a good place either, which signifies the scope of healthcare companies' expansion into this field to increase their sales.

The following question provides a straight review of marketing strategies and value-added services as outlined in the literature, intending to elicit their thoughts on how they interact with them in particular. To avoid the obviousness issue, the word marketing was not used, and a few examples of healthcare firms in the pharmaceutical industry were given to give them a perspective and to start their thought process in that direction. The 3-point scale was employed where the options were Like, Dislike, and Neutral to get a clear idea.

According to the study, (Table 2 and Figure 2) the simplicity of use and real-time order updates are the most significant elements for customers in this age group, while TV advertisements and recorded calls, which are considered classic marketing tactics, are among the least important considerations. Notably, contrary to what is indicated in the literature, celebrity engagement has no bearing. The fact that voluntary efforts are among the top might be the result of COVID-19 voluntary initiatives implemented by many firms, implying that COVID-19 has had a significant impact on customer behaviour.

The last two questions simply put forth other such aspects of marketing, shaping the inferences based on the responder's opinions. The term buying behaviour was iterated at the end of the survey to cross-verify the answers collected in the preceding questions. The results are found to be quite comparable, and so may be deemed genuine. (Figure 3)

The final task was to determine the method of getting portal updates, as this is the most significant aspect. Consumers must be kept informed of changes, and appropriate instructional resources must be readily available. According to the statistics presented in Figure 4, the majority of respondents either learn about the upgrades while using the service or are kept informed through media sources, which supports the theory.

\section{CONCLUSION}

In the preceding sections, the idea of marketing and its relevance in the pharmaceutical and healthcare industries were covered, as well as the details of marketing in this industry and the modifications/variations that occurred throughout COVID-19. The literature evaluation produced theoretical implications, which were subsequently turned into a survey questionnaire to confirm the facts.

COVID-19's impact on youth-targeted pharmaceutical marketing has been scientifically confirmed. This study indicates that while there has been a good move toward digital mode, there is still a lot of room for improvement, particularly in the healthcare industry. Even though the big figures are still relatively neutral, the endpoints are on the good side. They embrace this way of living in almost every area of their lives. There are still 
some stumbling blocks in the healthcare sector.

According to the findings, internet marketing and current marketing approaches have unquestionably assisted in the growth curve, while conventional marketing tactics are gradually losing their influence among the young. The reason for this is the quantity of time spent watching media channels. Media channels such as social media campaigns, trends, ads, and public relations are the most widely acknowledged and recognised methods for obtaining and updating information. In addition to the quick summary given in the current study, there is potential for going further into the consumer's thinking and understanding the components in greater depth.

The study's limitations include a small sample size, which can have a significant impact on the results, a geographical restriction to Delhi NCR, which can be a bias because digital media is used more frequently in metro cities than in rural and suburban areas, and a lack of pure statistical analysis, as only the overview and comparative data is considered here. In the future, researchers can stick to the study's core structure while incorporating newer approaches, removing as many restrictions and biases as possible to offer a comprehensive result.

\section{REFERENCES}

1. Anderson, S., Rayburn, S. W., and Sierra, J. J. (2019), "Future thinking: the role of marketing in healthcare", European Journal of Marketing, 53(8), pp. 1521-1545. https://doi.org/10.1108/EJM-10-2017-0779

2. Brantnell, A. (2019). "Lecture 2 in scientific Theory", Lecture 2 in Scientific Theory, pp. 1- 24. https://doi.org/10.4337/9781786439208.00012

3. Bryman, A., and Bell, E. (2011). Business Research Methods: Vol. Third.

4. Chaffey, D., and Ellis-Chadwick, F. (2016), "Digital Marketing: Strategy, Implementation and Practice”, Sixth Edition (6th ed.).

5. Chen, F.; Ghosh, A.; Lin, J.; Zhang, C.; Pan, Y.; Thakur, A.; Singh, K.; Hong, H.; Tang, S. (2020) "5lipoxygenase pathway and its downstream cysteinyl leukotrienes as potential therapeutic targets for Alzheimer's disease", Brain, Behavior, and Immunity, 88, pp. 844-855, https://doi.org/10.1016/j.bbi.2020.03.022.

6. Grbic, M., Stimac Grbic, D., Stimac, L., and Sostar, Z. (2019), "Digital marketing in healthcare", European Journal of Public Health, 29(Supplement_4), pp. 411412. https://doi.org/10.1093/eurpub/ckz186.077

7. Hakansson, H., and Shenota, I. (1995), "Developing relationships in business networks", Routledge, pp. 418. https://doi.org/10.1016/j.indmarman.2004.12.007

8. Kotler P., Kartajaya H., and I. S. (2017), "Marketing 4.0: moving from traditional to digital", In Journal of Chemical Information and Modeling, https://doi.org/10.1017/CBO9781107415324.004

9. Lai, T.H.T.; Tang, E.W.H.; Chau, S.K.Y.; Fung, K.S.C.; $\mathrm{Li}$, K.K.W. (2020) "Stepping up infection control measures in ophthalmology during the novel coronavirus outbreak: an experience from Hong Kong ", Arbeitsphysiologie, 258, pp. 1049-1055, https://doi.org/10.1007/s00417-020-04641-8

10. McCabe K. (2020), 51 Customer Review Statistics to Make You Rethink Using Them, https://learn.g2.com/customer-reviews-statistics

11. Meng, L.; Hua, F.; Bian, Z. (2020) "Coronavirus Disease 2019 (COVID-19): Emerging and Future Challenges for Dental and Oral Medicine", J Dent Res, 99, $\quad$ pp. 481-487, https://doi.org/10.1177/0022034520914246

12. Pistol, L., and Tonis Bucea-Manea, R. (2017), "The 7Ps and $1 G$ that rule in the digital world the marketing mix", Proceedings of the International Conference on Business Excellence, 11(1), pp. 759-769. https://doi.org/10.1515/picbe-2017-0080

13. Popovici, V., Muhcin, S., and Popovici Alina, L. (2018), "Traditional versus Online Marketing for B2B Organizations: Where the Line Blurs", Ovidius University Annals: Economic Sciences Series, XVIII(1), pp. 382-387

14. Ran, L.; Chen, X.; Wang, Y.; Wu, W.; Zhang, L.; Tan, X. (2020) "Risk Factors of Healthcare Workers With Coronavirus Disease 2019: A Retrospective Cohort Study in a Designated Hospital of Wuhan in China", Clinical Infectious Diseases, https://doi.org/10.1093/cid/ciaa287

15. Silverman, D. (2019). "IAB Internet Advertising Revenue Report", IAB, May https://www.iab.com/wpcontent/uploads/2016/04/IAB-Internet-AdvertisingRevenue-Report-FY-2015.pdf

16. Swift Y.B. (2019), "Do Your Patients Consult Google First? An Expert Interview”, https://www.empr.com/home/features/do-your-patientsconsult-google-before-they-consult-you-an-expertinterview-with-james-a-elizy-md/

17. Wagrell, S. (2018), "Markets, Marketing and Key Dimensions", Markets, Marketing and Key Dimensions, pp. 1-24.

18. Yi, Z. (2018), "The Marketing Mix and Branding”, In Marketing Services and Resources in Information Organizations, pp. 49-57. https://doi.org/10.1016/b9780-08-100798-3.00005-2 
FIGUES AND TABLES

\begin{tabular}{|l|c|c|c|c|c|}
\hline Factors & Always & Mostly & Often & Sometimes & Never \\
\hline Time & 70 & 82 & 38 & 15 & 5 \\
Product Variety & 66 & $86^{*}$ & 42 & 14 & 2 \\
Discounts/Offers & 66 & 79 & 38 & 22 & 5 \\
Quality & $89^{*}$ & 67 & 34 & 15 & 5 \\
Social Distancing & 63 & 66 & 46 & 25 & 10 \\
Health Condition & 53 & 64 & 43 & 35 & 15 \\
TV Ads & 25 & 44 & 56 & 46 & $39^{*}$ \\
Social Media & 32 & 57 & 61 & $47^{*}$ & 13 \\
Grievance Redressal & 42 & 58 & 59 & 39 & 12 \\
Using App/Website & 51 & 63 & $63^{*}$ & 24 & 9 \\
\hline
\end{tabular}

Table 1. Factors affecting consumer buying behaviour

\begin{tabular}{|l|c|c|c|}
\hline Marketing Aspects & Like & Neutral & Dislike \\
\hline Ease of Use & 154 & 47 & 9 \\
Real-time Order Updates & 127 & 66 & 17 \\
Voluntary Initiatives & 106 & 88 & 16 \\
Grievance Redressal & 78 & 112 & 20 \\
Social Media Campaigns & 75 & 107 & 28 \\
Emails about offers & 71 & 74 & 65 \\
App Notifications & 67 & 82 & 61 \\
Social Media Trends & 65 & 109 & 36 \\
TV Ads & 53 & 102 & 55 \\
Recorded Calls & 44 & 91 & 75 \\
Celebrity involvement & 21 & 116 & 73 \\
\hline
\end{tabular}

Table 2. Marketing and Value-Added Services

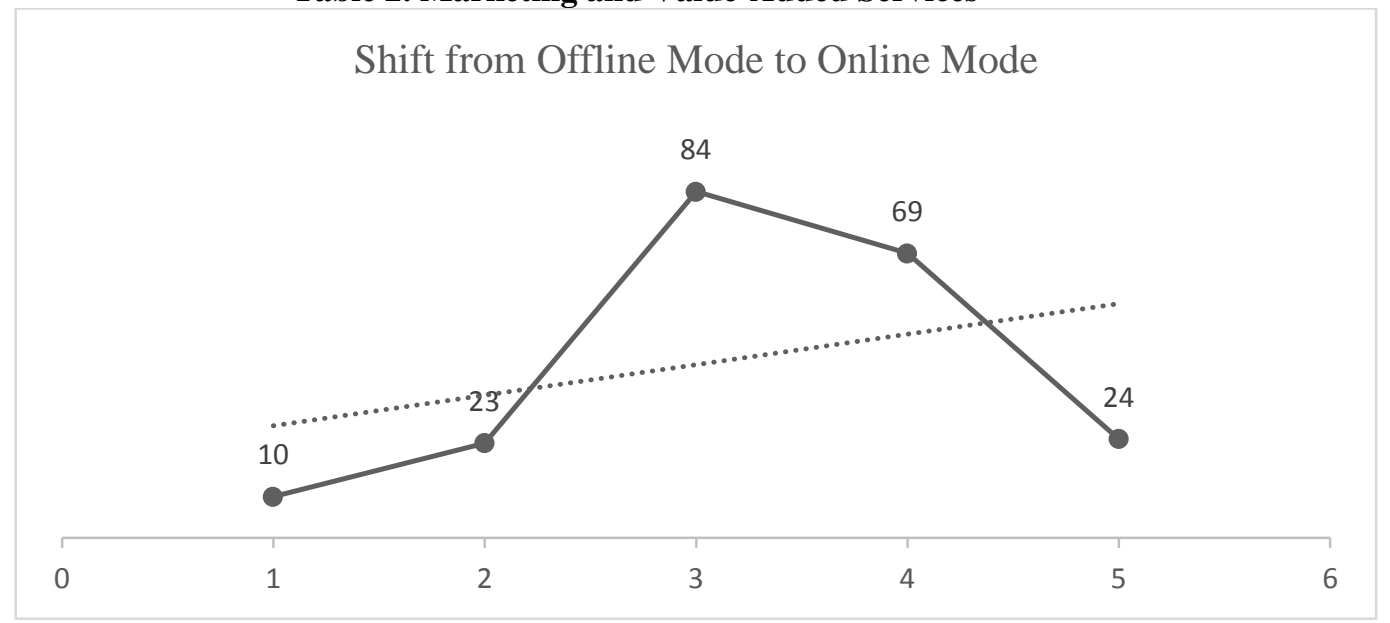

Fig 1. 5-Pointer scale rating $(1=$ Offline; 5 = Online $)$

\footnotetext{
${ }^{*}$ The category wise maximum value highlights the level of importance of a factor affecting consumer buying behavior.
} 


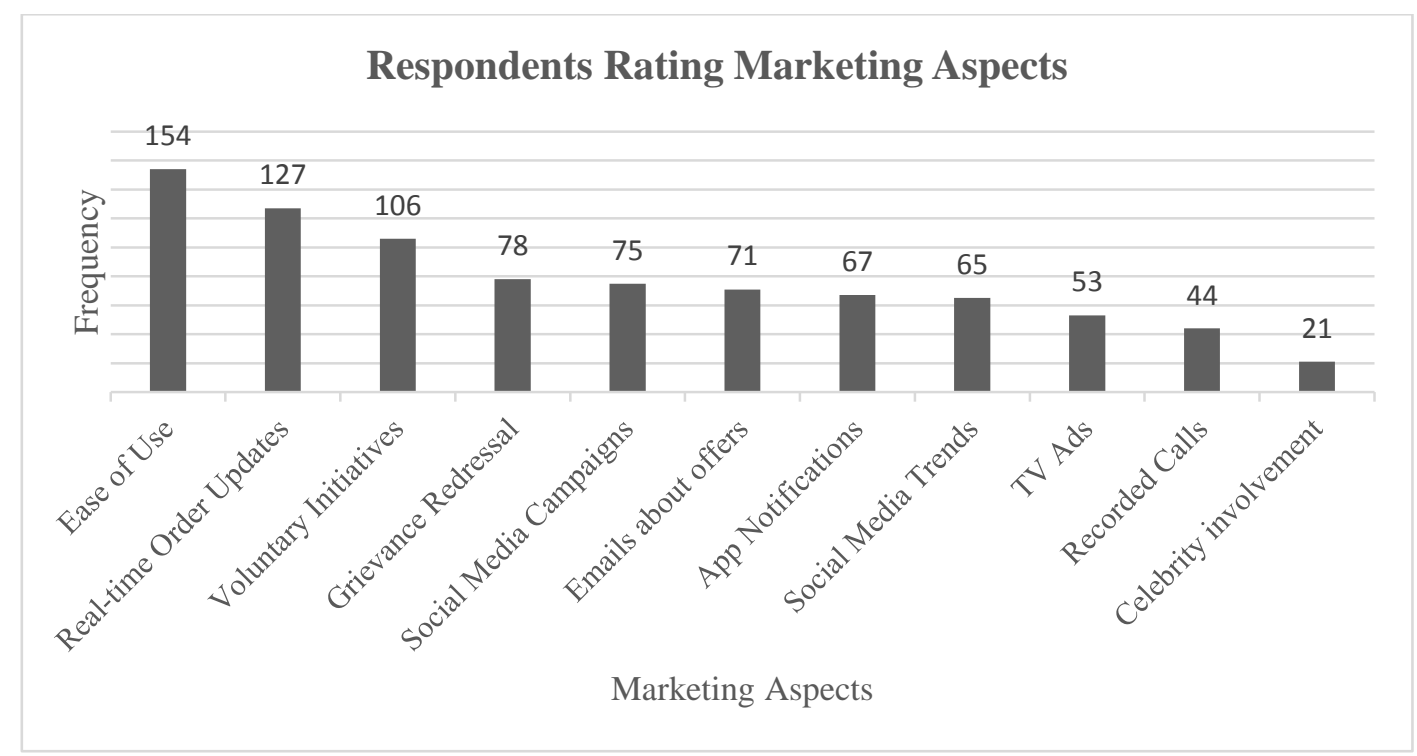

Fig 2. The decreasing trend of respondents liking an aspect

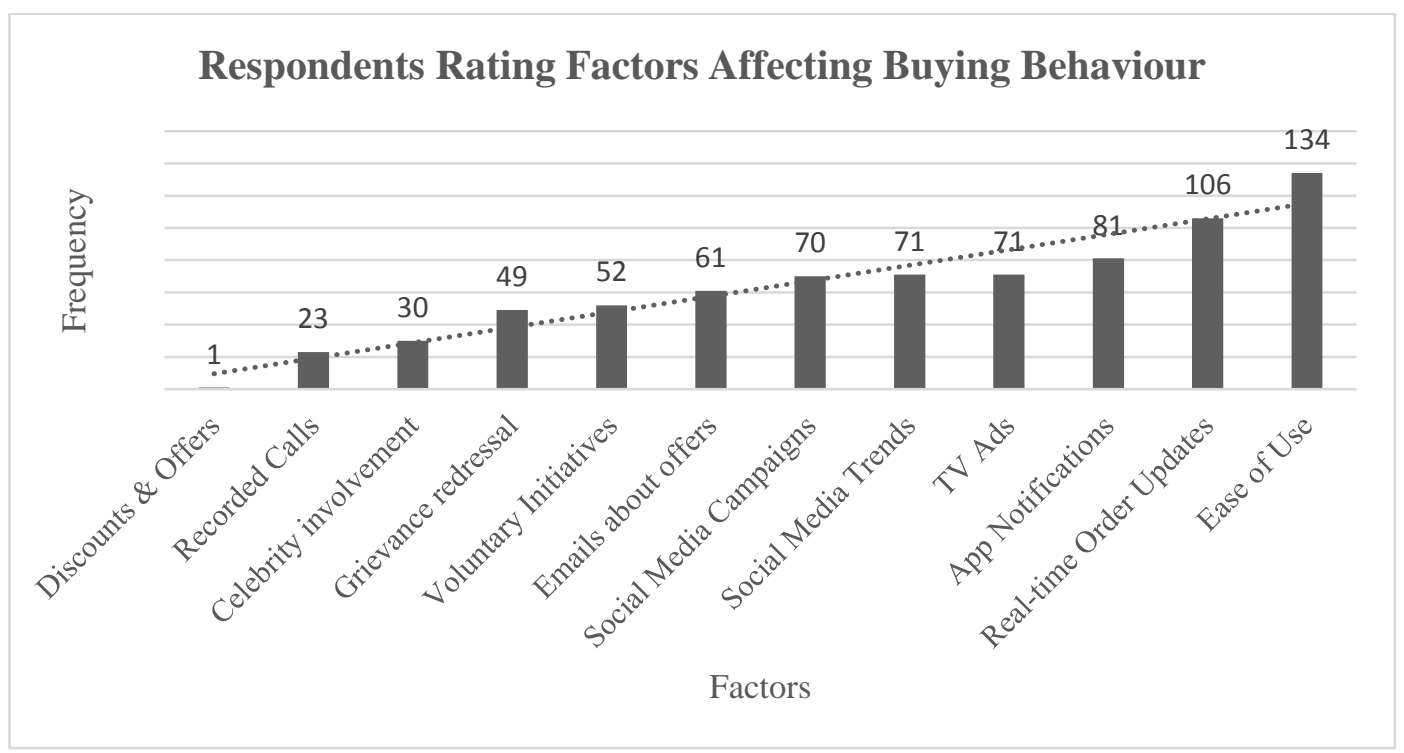

Fig 3. Traditional Vs. Modern factors affecting buying behaviour 


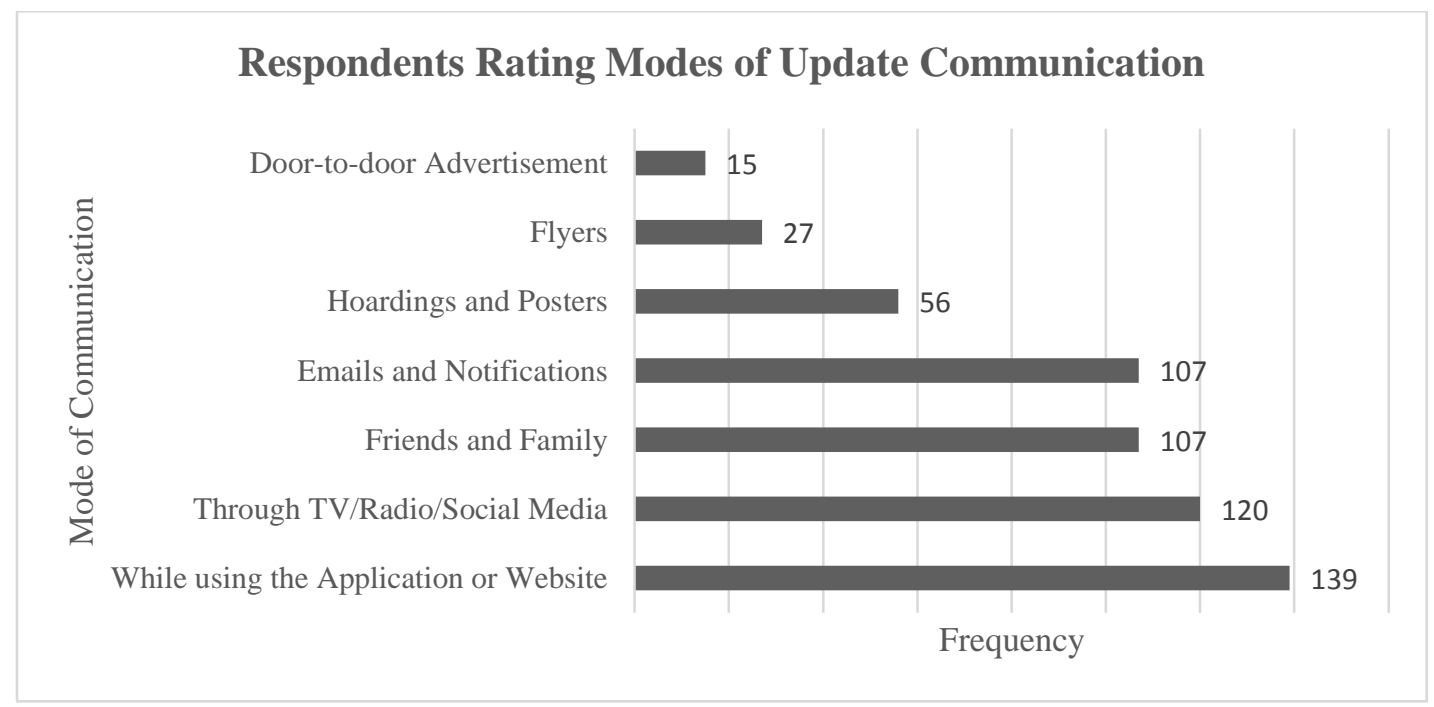

Fig 4. Mode of receiving website/application/portals updates 